\title{
Age differences in the learning of a conditioned visual avoidance task in male hooded rats
}

\author{
SOON-JUAN CHEE \\ University of Georgia, Athens, Georgia
}

(Michael S. Fanselow, Sponsor)

\begin{abstract}
Young rats have been shown to perform better on a conditioned avoidance task than do older rats. The present study examined how development in rats affected their rate of acquisition of the avoidance task. Male hooded rats, taken 10 days apart in age ranging from 80 days to 200 days, were treated on a visually conditioned avoidance task where the total number of avoidance responses were recorded. The results revealed that rats between 80 and 90 days performed significantly better than did rats between 100 and 150 days, which in turn did better on the avoidance task than did rats between 160 and 200 days of age.
\end{abstract}

The rate of acquisition of an avoidance task has been shown to differ among rats in different age groups. Specifically, Isaac and Baker (1963) showed that albino rats 100-120 days of age performed significantly better on a conditioned visual avoidance task than did rats $210-230$ days of age.

Chee and Isaac (1991) found similar results with hooded rats. Young rats approximately 100 days old showed more avoidance responses in a conditioned visual avoidance task than did rats about $\mathbf{2 0 0}$ days old. Thus, it is apparent that younger rats learn the avoidance task faster than do their older counterparts.

Age-related differences in rat behavior are not limited to avoidance learning. It has been consistently shown that younger rats (approximately 90 days of age) exhibit differences in locomotor activity, avoidance conditioning, recovery of function, cortical arousal levels, reaction times, and fixed-interval responding from older rats (Chee \& Isaac, 1991; Delay, 1982; Delay, 1985; Delay \& Isaac, 1983; Delay, Wenzel, \& Isaac, 1988; Isaac \& Baker, 1963; Kallman \& Isaac, 1975).

Neurological basis for such a difference in learning behavior is not widely documented. However, Delay et al. (1988) found that the EEG arousal levels of the occipital cortex of older rats were greater than those of younger rats. In an attempt to explain how such learning differences occur between young and older rats, Delay et al. suggested that the higher cortical arousal levels in older rats may act as an active inhibitory mechanism, affecting the rate of acquisition of the rats.

\footnotetext{
The author would like to express his gratitude to the late Dr. Walter Isaac, whose illness and subsequent death in June 1988 prevented him from collaborating in this research. The author would also like to thank William B. Pavlik and Walter L. Isaac for their helpful comments in the preparation of this manuscript. Correspondence should be addressed to Soon-Juan Chee, Department of Social Work and Psychology, National University of Singapore, 10 Kent Ridge Crescent, Singapore 0511, Republic of Singapore.
}

However, although there is much data on behavioral differences as a function of age, little information as to when the behavioral changes take place during the 100 odd days of development between young and old rats is available. Hence, the present study attempted to determine if the difference observed in the ability to learn an avoidance task between young and old rats occurred gradually between 100 and 200 days or if it occurred over a more specific age range.

\section{METHOD}

\section{Subjects}

A total of 130 male hooded rats from the breeding colony in the Animal Behavioral Laboratory of the Department of Psychology at the University of Georgia were used. The subjects belonged to 10 age groups between 80 and 200 days, and each group consisted of 10 rats. Prior to testing, each rat was housed individually for at least $24 \mathrm{~h}$ in the colony and was maintained on a 12:12-h light:dark schedule, with light onset at 6 a.m. Food and water were available ad lib throughout the experiment.

\section{Apparatus}

The apparatus employed was similar to that described by Isaac and Baker (1963). It consisted of a $70 \times 70 \times 40 \mathrm{~cm}$ box (covered by a glass plate) divided into four quadrants by $6-\mathrm{cm}$-high hurdles. The floor of the box, formed by brass bars that also ran along the top of the hurdles, could be electrified. A 200-W light bulb in a standard porcelain reflector was suspended $20 \mathrm{~cm}$ above the glass plate cover and provided illumination of $130 \mathrm{fc}$ at the outer edge of the floor. A door buzzer was located at the base of the bulb. Throughout each testing session, illumination was provided by a 15-W light bulb directed upward and shielded by a reflector. The testing room was sound shielded. The ventilation system provided a constant masking sound.

\section{Testing Procedure}

At the beginning of a testing session, each rat was placed in the conditioning apparatus and allowed to explore its new environment for $5 \mathrm{~min}$ before the beginning of the conditioning trials. At the beginning of each trial, the 200-W light bulb was switched on until the rat crossed over the hurdle into another quadrant. If such a response did not occur in $4 \mathrm{sec}$ after the onset of the increased illumination, the grid floors and hurdles were electrified. This was accompanied by the sound of the buzzer. The shock and sound were simultaneously stopped only after the rat crossed into another quadrant. Each such trial was initiated and 


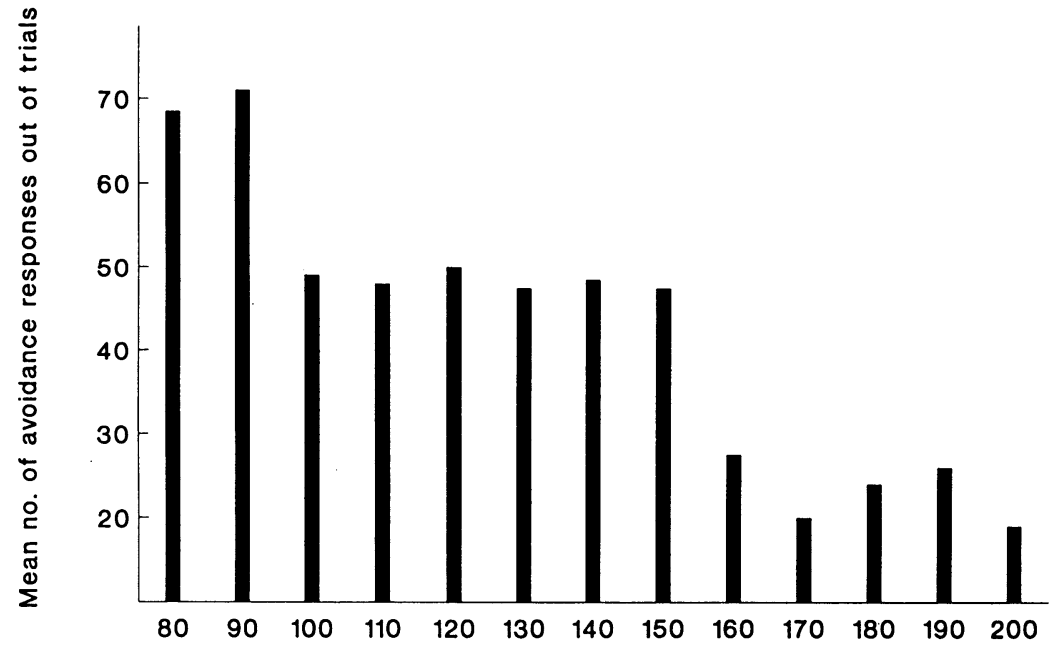

Age (days)

Figure 1. Mean number of avoidance responses of rats in different age groups.

terminated manually by the experimenter. The sequence and preshock interval were electronically controlled. The trials were presented on a variable-interval schedule of $20 \mathrm{sec}$. An avoidance response occurred when the rat crossed a hurdle into another quadrant during the onset of the light before the electric shock was delivered. Each rat was given 100 trials, and the number of avoidance responses was recorded. The animals were tested between 6 and 11 p.m.

\section{RESULTS}

A one-way analysis of variance of the data showed that the overall $F$ ratio was significant at the .001 level $[F(12,117)=6.41]$.

A post hoc analysis using Duncan's multiple range test revealed that 90 -day-old rats performed better (i.e., they showed more avoidance responses) than did 100-day-old rats, and 150-day-old rats in turn outperformed 160-dayold rats. These differences were significant, at least at the .05 level. No significant differences were found for rats between 80 and 90 days, between 100 and 150 days, and between 160 and 200 days of age.

The mean scores for the number of avoidance responses for the different age groups are shown in Figure 1.

\section{DISCUSSION}

The data indicate that rats from 80 to 90 days old learned the avoidance task more successfully than did rats between 110 and 200 days old. Rats between the ages of 110 and 150 days in turn did better than rats between 160 and 200 days old. The differences in the learning ability seemed to occur between a rather narrow age range of about 10 days.

If such an age-related mechanism does affect the learning ability of older rats, removal of this inhibitory effect should enhance the performance of these animals concerning the acquisition of the visually mediated avoidance task. This was exactly what Isaac and Baker (1963) found, and the results were subsequently replicated by Chee and Isaac (1991). Both of these studies showed that when the occipital cortex was removed in older rats (approximately $\mathbf{2 0 0}$ days old), the acquisition rate of these rats on the avoidance task improved.

Evidently, 90-day-old rats are not as representative of older rats as we assume. Hence, to use them as models to encompass the entire range of "sexually mature" rats would not be meaningful.

Furthermore, in view of the present data where behavioral differences have been found in rats varying in age by as little as 10 days, age ranges of rats used in research are of critical importance. Indeed, studies using animals over wide age ranges may well be suspect to developmentalrelated confounds.

Collectively, these data strongly suggest that the behavior, as well as the neurophysiology, of the "adult" rat may be less uniform and consistent than expected.

\section{REFERENCES}

Chee, S. J. \& IsAac, W. (1991). The effects of occipital ablation on a visually conditioned avoidance task in young and old rats. Physiology \& Behavior, 49, 481-484.

Delay, E. R. (1982). Age-related differences in the effects of d-amphetamine and illumination on fixed-interval responding of rats. Psychopharmacology, 78, 298-299.

DeLay, E. R. (1985). Interactive effects of noise with illumination and age on activity of rats. Perceptual \& Motor Skills, 60, 479-483.

Delay, E. R., \& IsAAC, W. (1983). Age and arousal in the rat. Bulletin of the Psychonomic Society, 21, 294-296.

Delay, E. R., Wenzel, D. M., IsaAC, W. (1988). Age changes in electrophysiological measures of the superior colliculus and occipital cortex. Physiology \& Behavior, 42, 163-166.

IsAAC, W., \& BAKER, E. J. (1963). A changing effect of cortical ablation with age. Journal of Comparative \& Physiological Psychology, 56, 167-168.

Kallman, W. M., IsaAc, W. (1975). The effects of age and illumination on dose-response curve for three stimulants. Psychopharmacologia, 40, 260-264.

(Manuscript received September 25, 1991.) 